\title{
Study of teachers' preparedness for professional activities in an inclusive educational environment
}

\author{
L.S. Pilipchuk ${ }^{1}$, A.S. Kovaleva ${ }^{2 *}$, and Y.B. Karnauhova ${ }^{3}$ \\ ${ }^{1}$ Altai State Pedagogical University, Barnaul, Russia \\ ${ }^{2}$ Altai State Pedagogical University, Barnaul, Russia \\ ${ }^{3}$ Altai State Pedagogical University, Barnaul, Russia
}

\begin{abstract}
The article presents the results of a study on the psychological preparedness of teachers and students of the pedagogical universities to work with children with disabilities within the conditions of inclusive education. The features of the personal component in the structure of psychological preparedness for professional activities are considered. The description of the two stages and the results of the study carried out by the workers of Diagnostics and correction of developmental disorders of children.
\end{abstract}

\section{A problem statement}

An urgent problem of modern education is the formation of the requisite level of preparedness of a teacher for professional activities with children with disabilities in an inclusive educational environment. The organization of inclusive education qualitatively changes and expands the requirements for the activity of the teachers, their functional duties, influencing changes in occupationally relevant and personal characteristics. Inclusive preschool education is aimed at the processes of teaching, upbringing, growth, and development of children with special educational needs alongside with children of regular development within a single educational space for their intellectual, spiritual, moral, creative, and physical development, the satisfaction of educational needs and interests, which is based on the principles that create conditions for children with special educational needs. Inclusive preschool education has its own ideology, concept and provides a certain strategy - planning, technology [1-6].

\subsection{The objective of the work}

This raises the relevant question of the psychological and personal preparedness of the teacher for professional activities. In Russian studies psychological preparedness [7-11] is understood as a mental phenomenon that explains the stability of a person's activity in a polymotivated space: in the form of attitudes (as a projection of past experience on the

*Corresponding author: prof-ped.gpa@mail.ru 
situation "here and now"), conscious assessments of the situation and behavior caused by previous experience; in the form of motivational readiness (the ability to realize the meaning and value of what he does); in the form of professional and personal preparedness for self-realization through the process of personalization, Psychological preparedness can be treated as a set of internal and external conditions. Primarily, these are the personal qualities of the teacher that ensure preparedness for professional activities, such as intellectual, motivational, emotional-volitional, professional, and value-based qualities. These are inner confidence and determination, developed during professional training state of mobilization which facilitates successful and effective performance. At the same time, psychological preparedness is one of the conditions for the effectiveness of the professional activity [10-12]. The following components could be distinguished within the structure of professional preparedness of a teacher for work with children with disabilities in an inclusive educational organization: understanding the philosophy of inclusive education, knowledge of psychological and pedagogical patterns and features of age and personal development of children with disabilities; or [10, 11]: motivational; cognitive including knowledge in the sphere of inclusive education; effective, understood as a set of skills and abilities needed to implement inclusive education; reflexive including certain personal qualities of a teacher that are significant for inclusive education. The teacher's preparedness for inclusive education of preschool children is the basic condition for the successful implementation of inclusive education of preschool children, dynamic, integrative professional and personal education, characterized by the presence of an attitude that assumes an active predisposition and the teacher's need for the implementation of inclusive education of preschool children, manifested in the availability and mobilization of special knowledge, skills, and skills for the implementation of inclusive education. Professional preparedness manifests itself in the teacher's conscious direction and in his/her ability to perform professional activities that fully address the educational needs of a child within the inclusive educational environment $[10,11,13]$.

\section{Results of the research}

In our study, the structure of professional preparedness of teachers for inclusive education of children is considered as a dynamic education which includes such content components as: personal and semantic (the teacher's reflexive attitude to the adoption of the ideology of inclusive education, the motivational orientation of the teacher's consciousness, will, and feelings towards inclusive education of children), cognitive (a set of professional and pedagogical knowledge necessary for inclusive education of children) and technological (a set of professional and practical skills for implementing inclusive education for preschool children) $[11,13]$

This article presents the results of a study of the personal component of the teacher's professional preparedness, conducted by the staff of the laboratory "Diagnosis and correction of developmental disorders of children with Disabilities" of the Institute of Psychology and Pedagogy of AltSPU (2018-2020).d) and consisting of two stages. At the first stage, were studied the features of personality within the structure of the preparedness of teachers of inclusive preschool educational organizations to work with children with disabilities through studying the following individual psychological characteristics: attitudes, value and conceptual ideas of self-perception (assertive solving of professional problems, the need for personal and professional growth) and personal professional activity; perception and awareness of the difficulties and barriers of inclusive teaching practices. 
The second stage of the work is aimed at the study of inclusive culture formation potential of future teachers (university students) and practical evaluation of the preventive program.

The first stage of the study was conducted in Barnaul and Novoaltaysk educational institutions in 2018-2019. The study sample consisted of preschool teachers implementing inclusive education. The sample size is 75 people, aged from 28 to 58 years with work experience from 7 to 36 years, all teachers have completed professional retraining courses on defectology, have little experience working with children with disabilities (3 years), as they worked with children of general development until 2016. We used the semantic differential, which belongs to the methods of experimental psychosemantics and is one of the ways to construct subjective semantic spaces. In this work, we used the version of the semantic differential developed by Petrenko V.F. [14]; the data obtained with the help of the semantic differential reflects the subjective, emotional, and semantic representations of a person about himself/herself and other people, relationships, attitudes.

Using Semantic Differential, we evaluated the subjects ' subjective perception of themselves, their immediate social environment, and interaction in their professional activities, taking into account the main professional barriers and difficulties of the inclusive education system. For data processing, Microsoft Office Excel packages were used; SPSS (t-Student's test; U-Mann-Whitney test; correlation analysis; factor analysis).

With the aim of exploring the peculiarities of the perception of professional activity and professional behavior of the individual through the analysis of value-semantic attitudes of consciousness, unipolar evaluation scales were developed, which were offered to the respondents. Situations of a teacher's professional activity in an inclusive educational environment were used as assessment scales-descriptions in the study. Situations (22 rating scales) were selected in the course of a preliminary survey of respondents, who noted them as the most professionally important and relevant in the preschool organization practice, causing both emotional stress and vice versa, stimulating professional activity. Eight characters were chosen as the objects of assessment, reflecting: the self-system and its concepts of different time periods, as well as the social environment of the preschool teacher defined as a repertoire of roles: "I am", "I was 3 years ago", "I am in 3 years period"; "preschool teacher"; "educational psychologist"; "speech therapist"; "special education teacher"; "Administration of a preschool educational institution". The total group data matrices $(8 \times 22)$ were subjected to the factor analysis procedure.

The results obtained during the factor analysis of the data allowed us to distinguish 4 factors; more than $65 \%$ of the total variance is accounted for by two bipolar factors, the general description of which is reflected in this paper. The leading bipolar factor F1 was estimated by the following scales: "experiencing problems of regulatory activities" (0.98), "too much paperwork" (0.96), "difficulties of interdisciplinary interaction" (0.96), "experiencing a state of emotional stress at work" (0.91), "not enough patience to delve into the problems of professional activity" (0.90), "not enough professional knowledge" (0.89); its opposite pole is set by the following scales: "in professional activity, focused on positive dynamics in the development of the child" (-0.79), "receives support from the administration" (-0.77), "has the necessary competencies to work with children with disabilities" (-0.69). We identified this factor as a factor in assessing the current barriers to the professional activity of a preschool teacher. The second identified bipolar factor (F2) was interpreted as "social activity", its poles were: "needs further training" (0.78), "insufficient narrow knowledge of various types of disorders" (0.75); the opposite pole "sees prospects for further growth" (-0.67), "has competencies for working with children with disabilities" (-0.62) - it can be noted that the respondents identify as the most significant those situations that are related to the development of professional competencies 
for working with children with disabilities and situations related to the development of emotional self-regulation, stress tolerance in the activity.

Assessment of the images according to their placement in the semantic space, showed that the most socially active images are the "administration" and "educational psychologist" images, the connection of these images is emphasized by high correlation coefficients (from 0.9 to 0.98 ); "I am" and "preschool teacher" images received low valuation. The image of "I am" (Table 1) correlates with the image of "preschool teacher" (0.96), has a low relationship with the images of "educational psychologist" (0.37), "special education teacher" (0.31), "administration of a preschool educational institution" (0.22), which are considered as the most active, successfully implementing themselves in situations of solving problems of inclusive practice.

Table 1. Fragment of the intercorrelation matrix of role positions.

\begin{tabular}{|l|l|l|l|l|l|l|}
\hline \multicolumn{1}{|c|}{$\begin{array}{c}\text { Role } \\
\text { positions }\end{array}$} & I am & $\begin{array}{c}\text { I was 3 } \\
\text { years ago }\end{array}$ & $\begin{array}{c}\text { I am in 3 } \\
\text { years } \\
\text { period }\end{array}$ & $\begin{array}{c}\text { preschool } \\
\text { teacher }\end{array}$ & $\begin{array}{c}\text { educational } \\
\text { psychologist }\end{array}$ & $\begin{array}{c}\text { speech } \\
\text { therapist }\end{array}$ \\
\hline I am & 1 & & & & & \\
\hline $\begin{array}{l}\text { I was 3 years } \\
\text { ago }\end{array}$ & 0.581801 & 1 & & & & \\
\hline $\begin{array}{l}\text { I am in } 3 \\
\text { years period }\end{array}$ & 0.415634 & 0.468914 & 1 & & & \\
\hline $\begin{array}{l}\text { preschool } \\
\text { teacher }\end{array}$ & 0.968636 & 0.548996 & 0.810499 & 1 & & \\
\hline $\begin{array}{l}\text { educational } \\
\text { psychologist }\end{array}$ & 0.372792 & 0.56803 & 0.559264 & 0.407141 & 1 & 1 \\
\hline $\begin{array}{l}\text { speech } \\
\text { therapist }\end{array}$ & 0.46328 & 0.374015 & 0.484636 & 0.386383 & 0.988197 & \\
\hline $\begin{array}{l}\text { special } \\
\text { education } \\
\text { teacher }\end{array}$ & 0.319207 & 0.195543 & 0.553273 & 0.353471 & 0.905245 & 0.900388 \\
\hline $\begin{array}{l}\text { administration } \\
\text { of a preschool } \\
\text { educational } \\
\text { institution }\end{array}$ & 0.22523 & 0.481551 & 0.504693 & 0.233288 & 0.937673 & 0.953395 \\
\hline
\end{tabular}

The analysis of semantic spaces showed that personal professional development is associated with the manifestation of directly opposite tendencies: the perception of the need to develop professional competencies and the awareness (analysis) of the barriers to professional activities.

Statistical processing of the data made it possible to differentiate teachers into groups according to the specific features of the psychological characteristics identified. 4 groups were identified within the studied sample: group $1(21 \%)$ - respondents with a low assessment of their "self-image" as a professional and the presence of a mismatch in the temporal positions of the "self-image" ("present self" is focused on "past self" ); Group 2 $(25 \%)$ - a low assessment of their "self-image" as a professional; Group $3(42 \%)$ : assessment of their "self-image" as active and successful in professional activity; ("present self" focused on the "future self") Group 4 (12\%) - a high assessment of the "self-image", confidence in their ability to meet professional challenges.

Analysis of the data shows that up to $46 \%$ of teachers implementing inclusive education in pre-school organizations demonstrate a low level of personal preparedness, they evaluate their professional skills and problem-solving abilities used in the process of pedagogical activities in the conditions of inclusive education as low. They note the need for psychological support and supervision of their activities by specialists in the sphere of 
defectologic education; they point out that they experience certain difficulties in interacting both with children with disabilities and their parents. 54\% of respondents have a high level of personal preparedness: they consider themselves prepared for situations of inclusive education and for solving practical educational tasks during the work process with preschool children with disabilities and their parents.

The results of the study can be used to develop preventive programs and programs of psychological and pedagogical support for teachers working in an inclusive educational organization. The organization of effective preventive work should include informing teachers about the inclusive education peculiarities system, psychological characteristics of teachers' work, and special techniques aimed at children with different types of developmental disorders, which contribute to the solution of difficult situations of professional activity [15-19]. A separate area of work should be the prevention of emotional disorders and the preservation of psychological health of the individual, the formation of professional values among teachers focused on achieving the humanistic goals of inclusive education.

The next stage of our study (2019-2020) was the practical evaluation of the preventive program. The workers of Diagnostics and correction of developmental disorders of children with Disabilities laboratory of the Psychological and Pedagogical Institute of Federal Governmental State-Financed Educational Institution of Higher Education AltSPU implemented a short-term project to study the potential for the formation of an inclusive culture (as a component of preparedness) of future teachers (university students).

Testing, qualitative and quantitative analysis of results were chosen as the methods of research. The sample consisted of senior students in Pedagogical Education, the number of respondents was 50 students in the experimental and control groups.

At the preparatory stage, two comparable groups of participants in the educational process were formed. At the next stage, a new factor - which was not provided to the control group - was introduced into the experimental group. This factor was the study of the basic Special Pedagogy and Psychology course with advanced treatment of the problems of inclusive education and the preparedness of future teachers for professional activities in an inclusive educational environment using specialized training manuals Technology for Creating a Tolerant Educational Environment (Barnaul, 2015) and Special Pedagogy and Psychology: Aspects of Tolerance Education in the Inclusive Conditions (Barnaul, 2017) written by A.S. Kovaleva [20, 21].

In order to identify the practical preparedness for interaction in an inclusive educational environment, the level of social distance was examined using the Social Distance Scale (E. Bogardus) - which is used to measure social distance considered as the degree of closeness or alienation between two groups of people. During the survey, the respondents marked the judgment that corresponded to the closeness they allowed with the members of the given group. Within the framework of our study, we investigated social distance concerning people with disabilities. To do this, respondents had to indicate a single correct statement (from 1 to 7 ) that could complete the following sentence: "Personally for me, it is possible to take a child with disabilities as...".

In the process of experimental work indicators of social distance and the degree of acceptance of children with disabilities underwent significant changes. The analysis of the results of the ascertaining measurements clearly demonstrates the predominance of the average social distance, which, on the one hand, is a positive indicator, but on the other hand, a high percentage of long social distance and a low level of acceptance $(32 \%$ and $34 \%$ in the control and experimental groups, respectively) bear a negative character. At the control measurements in the experimental group, the rate of acceptance and short social distance doubled, which was not observed in the control group. It is noteworthy that not only the general indicator of social distance in relation to children with disabilities has 
changed, but also the dynamics of this indicator on specific diagnostic scales. Thus, the distance increases, and the degree of acceptance decreases as the probability of communication with a child with disabilities penetrates into the close environment of the individual. While it is still possible to accept a child with disabilities as a citizen at an intermediate level, from the 'classmate' and 'friend' scales up to the 'relative' scale, the length of distance increases as much as possible. Positive dynamics were noted in the experimental group on all diagnostic scales, except for the "relative" scale. However, it should be noted that it has been no part of our aim to make changes on this scale and is considered to be impossible in such a limited period of time. The aim was to reduce the distance and increase the acceptance of the child with disabilities as a pupil, classmate, and friend at school, and this was achieved.

In the course of our study of the current state of the problem of the preparedness of future teachers for professional activities in an inclusive educational environment, the relevance of work in this direction has been confirmed, and ways to increase its effectiveness have been identified. We propose to study the corresponding Special Pedagogy and Psychology course using special training manuals in the educational process, the formulated provisions of which and the effectiveness of the changes made to the pedagogical space were revealed during the testing.

As a result of purposefully organized interaction in the work process among future teachers, the nature and quality of the formation of the main components of preparedness for professional activities in conditions of inclusion changed, and the basic inclusive culture forming aspects such as: motivational, which presupposes the presence of a set of attitudes towards positive perception of people with disabilities, the possibility of communication and co-education; cognitive - the presence of correct ideas about children with disabilities, their capabilities, and characteristics; activity-based - the formation of constructive communication skills in a situation of intense interpersonal interaction; reflexive - an opportunity to assess the success of this interaction, to change the level of social distance and the degree of acceptance of a child with disabilities.

The preparedness of teachers (both future and already experienced) for professional activities in an inclusive educational environment is an urgent need of modern social reality and psychological and pedagogical theory and practice. In the course of a detailed theoretical study of the designated problematic field, it became possible to determine the essence of the social approach in understanding inclusion, which focuses primarily on the need to overcome existing barriers (social, legal, cultural, architectural, etc.) that isolate people with disabilities from society, which prevents effective educational and social integration. It becomes obvious that it is necessary to design a social and educational environment through the implementation of psychological and pedagogical support for people involved in the educational process in order to maximize the potential of children with disabilities.

\section{Conclusions}

According to the general theoretical approaches, the educational environment is a set of material factors of the educational process and the interpersonal relationships that are established by the subjects of education in the process of their interaction. In turn, an inclusive educational environment is based on the following components: participants in educational relations who have equal rights; an architectural environment that provides mobility, awareness, safety, comfort; interpersonal relationships based on the principles of partnership, respect, mutual assistance and constructive communication; organization of training practice, taking into account individual characteristics and acceptance of differences of students. 
An inclusive educational environment, in turn, can be created only through the active cooperation and team interaction of all participants in the educational process, through the formation of a certain level of personal readiness and a new type of culture - inclusive, which is presented as a special system of relationships of all subjects of educational relations, a special philosophy, according to which values, knowledge about inclusive education are accepted by all participants in educational relations, which contributes to the creation of a unique microclimate of trust, comfort, support, acceptance of diversity, mutual understanding and partnership.

\section{References}

1. S.V. Alyokhina, Training of teaching staff for inclusive education, Bashkortostan pedagogical journal, 1(44), 26-32 (2013)

2. N.V. Alyokhina, M.N. Alekseyeva, E.L. Agaphonova, The preparedness of teachers as the main factor in the success of the inclusive process in education, Psychological Science and Education, 1, 83-92 (2011)

3. N.Ya. Semago, Inclusive preschool: the activities of specialists Sphera, 128 (2012)

4. E.V. Ketrish, Formation of the design competence of future teachers in the process of continuous pedagogical practice, 181 (2013)

5. D.A. Lipsky, A. Gartner, Achieving full inclusion: Placing the student at the center of educational reform, Controversial issues confronting special education: Divergent perspectives, 3-12 (1992)

6. E.-H Mattson, A.-M. Hansen, Inclusive and exclusive education in Sweden: principals' opinions and experiences, European Journal of Special Needs Education, 24, 4, 465-472 (2009)

7. N. Nazarova, Integrated (inclusive) education: genesis and implementation problems, Social pedagogy, 1, 77-87 (2010)

8. V.I. Lopatina, Wide aspects of inclusive education, Education and training of children with developmental disorders, 6, 11-13 (2009)

9. N.N. Malyarchuk, L.M. Volosnikova, Of teachers' willingness to work in inclusive education, Bulletin of the Tyumen State University. Humanities research, 4(4), 251267 (2015)

10. O.S. Kuzmina, Features of the organization of training teachers for work in inclusive education, Inclusive (integrated) education: from theory to practice: collection of articles, 39-48 (2013)

11. V.V. Khitryuk, Inclusive readiness of teachers: the pedagogical formation system, $176(2015)$

12. I.G. Marakushina, Psychological aspects of the problem of resistance to innovation in education, Bulletin of the Northern (Arctic) Federal University. Series: Humanities and Social Sciences, 5, 141-147 (2011)

13. L.S. Pilipchuk, E.V. Zhilkina, Psychological preparedness of students of a pedagogical university for professional activity in an inclusive education, Bulletin of AltSPU, 43, 59-66 (2020)

14. V.F. Petrenko, Psychosemantics of consciousness Moscow State University, 208 (1988) 
15. T.P. Skripkina, Y.V. Selezneva, Professional deformations of teachers under different types of trust relationships in preschool organizations, Voprosy psychologii, 4, 53-64 (2017)

16. V.A. Bodrov, Psychological stress: development and overcoming, 528 (2006)

17. B.B. Boyko, The energy of emotions in communication, 154 (1996)

18. K.T. Aprile, B.A. Knight, Preservice Teachers' Perceptions of Inclusive Education: The Reality of Professional Experience Placements, Australasian journal of special and inclusive education, 2(44), 88-101 (2020)

19. V. Moosa, M. Shareefa, M.D. Adams, A. Mohamed, Assessing Teacher Readiness for Inclusive Education in Maldives: Instrument Modification and Validation, International journal of disability development and edication (2020)

20. A.S. Kovaleva, Practical recommendations for organizing the upbringing of a culture of tolerance in the context of inclusive education, Problems of modern pedagogical education, 58-1,116-120 (2018)

21. A.S. Kovaleva, Creation of a tolerant environment and the formation of an inclusive culture of participants in the educational process: theoretical and practical aspects, Mir of Nauki, Culture, Education, 4(71), 266-268 (2018) 